University of Nebraska - Lincoln

DigitalCommons@University of Nebraska - Lincoln

USDA Wildlife Services - Staff Publications

U.S. Department of Agriculture: Animal and Plant Health Inspection Service

2018

Potential secondary poisoning risks to non-targets from a sodium nitrite toxic bait for invasive wild pigs

\author{
Nathan P. Snow \\ USDA/APHIS/WS/National Wildlife Research Center, nathan.p.snow@aphis.usda.gov \\ Justin A. Foster \\ Kerr Wildlife Management Area \\ Eric H. VanNatta \\ USDA/APHIS/ Wildlife Services, National Wildlife Research Center \\ Katherine E. Horak \\ USDA/APHIS/ Wildlife Services, National Wildlife Research Center \\ Simon T. Humphrys \\ Invasive Animals CRC
}

See next page for additional authors

Follow this and additional works at: https://digitalcommons.unl.edu/icwdm_usdanwrc

Part of the Life Sciences Commons

Snow, Nathan P.; Foster, Justin A.; VanNatta, Eric H.; Horak, Katherine E.; Humphrys, Simon T.; Staples, Linton D.; Hewitt, David G.; and Vercauteren, Kurt C., "Potential secondary poisoning risks to non-targets from a sodium nitrite toxic bait for invasive wild pigs" (2018). USDA Wildlife Services - Staff Publications. 2038.

https://digitalcommons.unl.edu/icwdm_usdanwrc/2038

This Article is brought to you for free and open access by the U.S. Department of Agriculture: Animal and Plant Health Inspection Service at DigitalCommons@University of Nebraska - Lincoln. It has been accepted for inclusion in USDA Wildlife Services - Staff Publications by an authorized administrator of DigitalCommons@University of Nebraska - Lincoln. 


\section{Authors}

Nathan P. Snow, Justin A. Foster, Eric H. VanNatta, Katherine E. Horak, Simon T. Humphrys, Linton D. Staples, David G. Hewitt, and Kurt C. Vercauteren 


\title{
Potential secondary poisoning risks to non-targets from a sodium nitrite toxic bait for invasive wild pigs
}

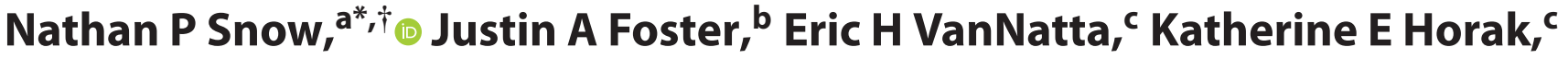 \\ Simon T Humphrys, ${ }^{d}$ Linton D Staples, ${ }^{d, e}$ David G Hewitt ${ }^{\mathrm{a}}$ and \\ Kurt C VerCauterenc
}

\begin{abstract}
BACKGROUND: An acute and orally delivered toxic bait containing micro-encapsulated sodium nitrite (MESN), is under development to provide a novel and humane technology to help curtail damage caused by invasive wild pigs (Sus scrofa). We evaluated potential secondary risks for non-target species by: testing whether four different types of micro-encapsulation coatings could reduce vomiting by invasive wild pigs, testing the levels of residual sodium nitrite (SN) in tissues of invasive wild pigs, testing the environmental persistence of $\mathrm{SN}$ in vomitus, and conducting a risk assessment for scavengers.
\end{abstract}

RESULTS: Micro-encapsulation coatings did not affect the frequency of vomiting. We identified no risk of secondary poisoning for non-target scavengers that consume muscle, eyes, and livers of invasive wild pig carcasses because residual SN from the toxic bait was not detected in those tissues. The risk of secondary poisoning from consuming vomitus appeared low because $\sim 90 \%$ of the SN was metabolized or broken down prior to vomiting, and continued to degrade after being exposed to the environment. Secondary poisoning could occur for common scavengers that consume approximately $\geq 15 \%$ of their daily dietary requirements of digestive tract tissues or undigested bait from carcasses of invasive wild pigs in a rapid, single-feeding event. The likelihood of this occurring in a natural setting is unknown. The digestive tracts of poisoned invasive wild pigs contained an average of $\sim 4.35 \mathrm{mg} / \mathrm{g}$ of residual $\mathrm{SN}$.

CONCLUSION: Data from this study suggest no risks of secondary poisoning for non-target species (including humans) that consume muscle, liver, or eyes of invasive wild pigs poisoned with a MESN toxic bait. More species-specific testing for scavengers that consume digestive tract tissues and undigested bait is needed to reduce uncertainty about these potential risks.

๑) 2017 Society of Chemical Industry

Keywords: feral swine; non-target risk; pesticide; sodium nitrite; secondary poisoning; Sus scrofa; toxicant; vomit; wild boar; wildlife damage management

\section{INTRODUCTION}

Invasive wild pigs (hereafter: wild pigs; Sus scrofa; also referred to as feral hogs, feral pigs, feral swine, or wild boars ${ }^{1}$ ) are a damaging invasive species spreading throughout North America, Australia, South America, Africa, and many island nations. ${ }^{2,3}$ Populations of wild pigs cause extensive damage to agricultural and natural landscapes, and are expensive to control using conventional methods of trapping or shooting. ${ }^{4-7}$ Additionally, these methods have not mitigated damage across large regions. ${ }^{8,9}$ Invasive wild pigs also serve as reservoirs of diseases, ${ }^{10,11}$ reduce plant species diversity through rooting, ${ }^{12}$ depredate sensitive species, ${ }^{13-15}$ and destroy habitats for native species. ${ }^{16}$ As a consequence of these negative effects, a cost-effective means for controlling wild pigs, in the form of a toxic bait, is being developed for use in the United States, Australia, and New Zealand. ${ }^{17,18}$

Until recently, no toxic baits for wild pigs have been registered for use in the United States. In 2017, a toxic bait containing the active ingredient warfarin was registered by the United States Environmental Protection Agency (EPA), but has not been approved for use in any state. Warfarin causes death via diffuse hemorrhaging and is slow acting, therefore it has been deemed inhumane for wild

\footnotetext{
* Correspondence to: NP Snow, USDA/APHIS/WS/National Wildlife Research Center, 4101 LaPorte Avenue, Fort Collins, CO 80521-2154, USA.

E-mail:nathan.p.snow@aphis.usda.gov

$\dagger$ Current address: USDA/APHIS/ Wildlife Services, National Wildlife Research Center, Fort Collins, CO, USA.

a Caesar Kleberg Wildlife Research Institute, Texas A\&M University-Kingsville, Kingsville, Texas, USA

b Kerr Wildlife Management Area, Texas Parks and Wildlife Department, Hunt, Texas, USA

c USDA/APHIS/ Wildlife Services, National Wildlife Research Center, Fort Collins, Colorado, USA

d Invasive Animals CRC, Glenside, South Australia, Australia

e Animal Control Technologies Australia Pty Ltd, Somerton, Victoria, Australia
} 
pigs in Australia. ${ }^{19,20}$ Two other toxic baits containing the active ingredients sodium fluoroacetate (1080) or yellow phosphorus, respectively, are used on wild pigs in Australia (yellow phosphorus under a single state permit only), although both baits have generated concerns about humaneness and hazards for non-target species. ${ }^{17}$ Sodium nitrite (SN) was proposed as a new active ingredient for toxic bait for wild pigs that is considered humane with fewer non-target risks, ${ }^{17,18,21}$ and has been recently registered for use in New Zealand on wild pigs and common brushtail possums (Trichosurus vulpecula). ${ }^{18}$ Invasive wild pigs are highly susceptible to SN because they have lower levels of methemoglobin reductase enzymes compared to other mammals that protect against severe methemoglobinemia (i.e. blocking the uptake and transport of oxygen by red blood cells). ${ }^{17}$ Severe methemoglobinemia quickly induces unconsciousness and causes rapid and humane death from anoxia with minimal symptoms of distress (e.g. symptomatically similar to carbon monoxide poisoning). ${ }^{22,23}$

The use of toxic baits containing SN brings forth benefits and challenges. The main challenge is that $\mathrm{SN}$ is a highly reactive compound that must be pre-formulated to prevent it from reacting with bait substrates to be shelf-stable and effective. However, this instability has two clear benefits. Once SN is exposed to the environment, its rapid breakdown into less toxic and more aversive forms via the nitrogen cycle reduces the risks of secondary poisoning for scavengers. ${ }^{21}$ Also, SN does not bio-accumulate in tissues of animals because it is quickly metabolized or broken down, ${ }^{21}$ making SN an all-or-nothing toxin in which repeated sublethal exposures by scavenging animals are unlikely to have debilitating effects. ${ }^{17}$ Given these characteristics, a collaborative research effort between the Wildlife Services National Wildlife Research Center (NWRC, USA) of the United States Department of Agriculture, the Texas Parks and Wildlife Department (TPWD, USA), the Invasive Animal Cooperative Research Center (IACRC, Australia), Animal Control Technologies Australia (ACTA, Australia) Pty Ltd, and Connovation PTY Ltd (New Zealand) has developed an acutely toxic and highly effective lethal bait for wild pigs. ${ }^{24}$ This bait contains $100 \mathrm{mg} / \mathrm{g}(10 \%)$ of SN incorporated into an oil-based matrix primarily comprised of peanut paste. ${ }^{25}$

Though the benefits of SN in toxic baits for wild pigs are clear, research assessing secondary poisoning risks associated with deployment of SN toxic baits in natural settings, with an emphasis on non-target scavenger species in North America, is required. Secondary risks are expected to be low, because consuming common brushtail possum carcasses poisoned with $\mathrm{SN}$ toxic bait in New Zealand revealed no risks for domestic dogs, cats, and chickens. ${ }^{26}$ Other examinations of residual SN in carcasses of wild pigs were conducted via oral gavage using non-micro-encapsulated SN or prototype baits containing differing concentrations of $\mathrm{SN}_{,}{ }^{21}$ and may not reflect actual residue levels resulting from the consumption of the current bait formulation. In addition, consumption of SN appeared to cause vomiting by some wild pigs, ${ }^{21}$ which may affect lethality and generate risks of secondary poisoning for non-target species that could consume the vomitus. Prior to this study, it was not known if the frequency of vomiting or the potential risks of vomitus to non-target species could be reduced.

Our strategy for evaluating and attempting to minimize secondary risks incorporated the use of a micro-encapsulation coating around SN. ${ }^{18,27}$ This coating is used to protect SN from interacting with bait substrates and to mask the salty taste of SN which animals find aversive at lethal concentrations. When wild pigs consume a lethal dose of the micro-encapsulated SN (MESN), the micro-encapsulated coating quickly breaks down inside the digestive tract and releases SN into the blood to produce overwhelming methemoglobinemia. The timing and location of the release of SN in the digestive tract may affect the lethality, levels of residual $\mathrm{SN}$ in tissues and vomitus, and frequency of vomiting for wild pigs.

The objectives of this study were to evaluate the potential secondary risks of using MESN toxic bait to control wild pigs using four types of micro-encapsulation coatings. In particular, our goals were to reduce vomiting by wild pigs, reduce residual SN in carcasses of wild pigs, determine the environmental persistence of $\mathrm{SN}$ in vomitus, and evaluate potential risks of secondary poisoning for avian and mammalian scavengers. To meet these goals, we tested baits containing the four types of MESN on captive wild pigs, and evaluated for any reduction in vomiting and residual SN in carcasses. Results will be used to support the application for registration of a MESN toxic bait for wild pigs in the USA and Australia.

\section{MATERIALS AND METHODS}

We conducted the experimental trials in an outdoor research facility at the Texas Parks and Wildlife, Kerr Wildlife Management Area (KWMA), Hunt, TX, USA during January and May 2015. All wild pigs used in this study were wild captured from areas surrounding the KWMA. Upon arrival to Kerr WMA, we individually marked wild pigs with uniquely identifiable tags inserted in ears. The wild pigs were group housed in a $0.02 \mathrm{~km}^{2}$ ( $5 \mathrm{ac}$ ) outdoor holding pen for $\geq 2$ weeks prior to study initiation. This pen was constructed with steel-mesh perimeter fencing buried into the ground and contained naturally growing vegetation [e.g. oak (Quercus spp.) and cedar (Juniperus ashei) trees] and shade structures. We maintained the wild pigs on Bluebonnet ${ }^{\circledR} 18 \%$ Sow Ration Pellet (AC Nutrition, LP, Ardmore, OK, USA) provided at $3-5 \%$ of group body mass daily. This maintenance diet had a recommended feeding rate of $3 \%$ of body weight for growing swine. We provided water ad libitum from self-maintaining water troughs.

\subsection{Test substances}

We tested four formulations of proprietary micro-encapsulated coatings and a control formulation. This first treatment consisted of a water soluble, protein coating (Connovation Ltd, Auckland, New Zealand) applied to $\mathrm{SN}$ that is currently used in the prototype HOGGONE$^{\circledR}$ (ACTA, Victoria, Australia) for the USA and Australia, and in Bait-Rite Paste ${ }^{\circledR}$ (Connovation Ltd) in New Zealand. ${ }^{18,28}$ The second treatment consisted of a double coating of the first treatment resulting in a thicker coating in an attempt to delay absorption of SN into the bloodstream. The third treatment consisted of a soft wax coating that was insoluble in water (Southwest Research Institute, San Antonio, TX, USA). The fourth coating consisted of an acidic resistant resin specifically designed for enteric release of pharmaceuticals (Southwest Research Institute). Finally, the control treatment consisted of the first protein coating applied to sugar, instead of SN. The control group served as a baseline to assessing vomiting from non-toxic HOGGONE ${ }^{\circledR}$.

\subsection{Trial methodology}

We tested each of the four treatments on $n=6$ wild pigs, and we tested the control treatment on $n=4$ wild pigs. Prior to the tests, we moved the wild pigs into a sorting pen and randomly selected three pigs per day for testing allowing for three constraints among the treatment groups: (1) equal sex ratio among all treatments, 
(2) animal weights were between 20 and $40 \mathrm{~kg}$ to test subadults and adults, and (3) all animals appeared healthy and active. The selected wild pigs were fasted for $12 \mathrm{~h}$ prior to testing, although all animals had access to water and sparse vegetation in the pens.

We dosed each treatment animal with $400 \mathrm{mg} / \mathrm{kg}$ (body weight) of SN (not including the micro-encapsulation coating) which represented the estimated $\mathrm{LD}_{99}$ for wild pigs. ${ }^{17}$ The control animals were similarly dosed with $400 \mathrm{mg} / \mathrm{kg}$ (body weight) of sugar. Each treatment was hand-mixed into a bait matrix of peanut paste and crushed grains as found in $\mathrm{HOGGONE}^{\circledR}$, so that the concentration of SN (or sugar) was $10 \% \mathrm{w} / \mathrm{w}$ of the finished bait. We loaded the freshly prepared bait into $\mathrm{a} \sim 3.2 \times 45 \mathrm{~cm}$ polycarbonate pipe with rounded edges. The wild pigs were moved into a sorting chute and restrained with two animal control poles (The Ketch All Company, San Luis Obispo, CA, USA) secured around the upper snout. We inserted the pipe into the mouth of the focal wild pig and delivered the bait with a smaller, capped pipe. The bait was plunged slowly to allow the wild pigs to masticate and swallow. We observed each wild pig until mastication stopped to ensure that all bait was swallowed, and any bait dropped was redelivered. Dosing typically took 10-20 min per animal.

After each animal wholly consumed the bait, we immediately moved it into one of three adjacent observation pens measuring $\sim 1.5 \times 2 \mathrm{~m}$. Two observation towers were located directly above the observation pens so that researchers could observe each wild pig from $\leq 10 \mathrm{~m}$. We observed the treatment animals continually until death or until $4 \mathrm{~h}$ had passed. After $4 \mathrm{~h}$, the animals were checked every $15 \mathrm{~min}$. After $8 \mathrm{~h}$, the animals were checked approximately once per hour. Any treatment animals that survived for $\geq 24$ h were humanely euthanized via cranial gunshot. ${ }^{29}$ All control animals were humanly euthanized after $8 \mathrm{~h}$. Research activities involving the handling of animals were approved by the TPWD Institutional Animal Care and Use Committee (protocol \# 211010520151).

We recorded the time since dosing to first vomiting, death, and the frequency of vomiting for each animal. Once death occurred, we immediately collected five tissue samples (i.e. muscle from hind quarter, liver, eye, stomach, and small intestine). We rinsed the stomach and small intestine with water to remove any bait prior to freezing. We also collected two samples of undigested bait (i.e. stomach contents and vomitus if available). All samples were immediately vacuum sealed and frozen at approximately $-12^{\circ} \mathrm{C}$ to preserve the levels of residual SN. Vomitus was collected after the wild pig died to avoid disturbing the animal. The pens were thoroughly rinsed and scrubbed after each test to avoid any potential cross-contamination.

All tissue samples were analyzed by Southwest Research Institute using high-performance anion-exchange chromatography to quantify the concentration of residual nitrite. This method was calibrated using nine concentration points between $0.0001 \%$ and $0.02 \%$ of nitrite. The efficiency for recovery averaged $92.4 \%$ $(S D=22.2)$ and the method limit of detection was $0.00002 \%$ $\mathrm{w} / \mathrm{w}$. The undigested bait samples were analyzed by the USDA, National Wildlife Research Center (Fort Collins, CO, USA) using reverse-phase-ion-chromatography. This method was validated using samples containing $1 \%$ to $15 \%$ nitrite. The efficiency of recovery for nitrite averaged $92 \%(S D=2.4 \%)$ and the method limit of detection was $0.00036 \% \mathrm{w} / \mathrm{w}$. For all samples, if nitrite was not detected we reported the level to be consistent with the method limit of detection. We converted the concentrations of nitrite $(\mathrm{mg} / \mathrm{g})$ to $\mathrm{SN}$ to make inferences relative to the active ingredient.

\subsection{Environmental persistence of $\mathrm{SN}$ in vomitus}

After the above testing, we homogenized the samples of vomitus from all wild pigs for $15 \mathrm{~min}$ using a Brinkman Polytron PT 3000 homogenizer (Kinematica, Inc., Bohemia, NY, USA). We removed and placed approximately $2.1-4.7 \mathrm{~g}$ samples of the mixture into 132 individual plastic weigh boats $(40 \times 40 \times 8 \mathrm{~mm}$; Sigma-Aldrich, Darmstadt, Germany). We then immediately analyzed three randomly selected samples for an initial estimate of the residual concentration of SN (time $t=0$ ), using the methods described above for vomitus. We also immediately vacuum sealed and froze three samples at approximately $-12^{\circ} \mathrm{C}$ as controls for shelf-life in a freezer.

We split the remaining samples by placing half $(n=63)$ into one of two environmental chambers (Conviron model E7/2; Conviron, Winnipeg, Manitoba, Canada). Each chamber was set to follow a 12-h photoperiod using ultraviolet and incandescent light, or darkness. We set the temperature and relative humidity $(\mathrm{RH})$ to represent a hot and humid climate (e.g. typical of the south and south-east USA), or a moderate climate (e.g. typical of the midwest or west USA). Specifically, the hot and humid chamber was maintained at $35.2^{\circ} \mathrm{C}(\mathrm{SD}=0.4)$ and $92.4 \%(\mathrm{SD}=1.9) \mathrm{RH}$ during the day and $27.2^{\circ} \mathrm{C}(\mathrm{SD}=4.1)$ and $98.6 \%(\mathrm{SD}=4.3) \mathrm{RH}$ at night. The moderate chamber was maintained at $19.3^{\circ} \mathrm{C}(\mathrm{SD}=0.4)$ and $59.6 \%(\mathrm{SD}=3.3) \mathrm{RH}$ during the day and $11.3^{\circ} \mathrm{C}(\mathrm{SD}=3.8)$ and $67.6 \%(\mathrm{SD}=10.2) \mathrm{RH}$ at night.

From each chamber, we randomly selected and removed three samples at predetermined intervals. We examined for immediate trends by sampling at the hours of 1, 2, 3, 4, 5 and 6 post-initiation. Then, we examined for longer-term trends by sampling at the days of $1,2,3,4,5,6,7,8,9,10,15,20,25$ and 30 post-initiation. All samples were immediately vacuum sealed and frozen upon removal from the chambers at approximately $-12^{\circ} \mathrm{C}$. At the end of the sampling interval, all samples were thawed and analyzed for concentration of residual SN using the method described above for vomitus.

We accounted for evaporative loss in the samples through time by calculating and dividing the mass of $\mathrm{SN}$ at time $(t)$ by the mass of $\mathrm{SN}$ at $t=0$, to generate an overall proportion of $\mathrm{SN}$ relative to the beginning of the study. Mass at $t=0$ was calculated using the average concentration of $\mathrm{SN}$ detected from the six samples that were analyzed at time $t=0$.

\subsection{Data analysis}

We compared the proportion of wild pigs that vomited among the four micro-encapsulation treatments using a Fischer Exact Test in Program R (v3.3.1; R Foundation for Statistical Computing, Vienna, Austria). Then, we compared the residual concentrations of $\mathrm{SN}$ in the tissues and undigested bait among treatments using generalized linear models. For these analyses we used the control animals as our reference samples. We considered all statistical and biological differences among the reference and treatment groups at the level of $\alpha=0.05$.

For the environmental persistence of $\mathrm{SN}$ in vomitus through time, we compared the proportion of SN through time, relative to initial time $(t=0)$, and between climatic conditions, using beta regression (package betareg) in Program $R .{ }^{30}$ Specifically, we examined the interaction of time $\times$ climate to evaluate the cumulative effects of both conditions on the persistence of SN. We conducted two analyses of this interaction, the first to examine the immediate effects on persistence of SN during the first $6 \mathrm{~h}$. The second analysis examined the longer-term effects for 30 days. 
Table 1. Outcomes from invasive wild pigs consuming $400 \mathrm{mg} / \mathrm{kg}$ (body weight) of sodium nitrite in the toxic bait using four micro-encapsulation coatings in pens at the Kerr Wildlife Management Area, Hunt, TX, USA during 2014

\begin{tabular}{|c|c|c|c|c|c|c|c|}
\hline \multirow[b]{2}{*}{ Micro-encapsulation treatment } & \multirow[b]{2}{*}{$N$} & \multirow[b]{2}{*}{ Died } & \multirow[b]{2}{*}{ No. vomited } & \multicolumn{2}{|c|}{ Time to first vomit (h) } & \multicolumn{2}{|c|}{ Time to death (h) } \\
\hline & & & & Mean & SE & Mean & SE \\
\hline Protein (single) & 6 & 6 & 4 & 1.90 & 0.20 & 2.37 & 0.24 \\
\hline Protein (double) & 6 & 6 & 3 & 2.26 & 0.24 & 2.77 & 0.15 \\
\hline Soft wax & 6 & 6 & 5 & 2.55 & 0.23 & 2.93 & 0.28 \\
\hline Resin & 6 & 5 & 5 & 9.99 & 2.48 & 12.44 & 4.66 \\
\hline Control & 4 & 0 & 0 & NA & NA & NA & NA \\
\hline
\end{tabular}

Table 2. Means $(\mathrm{mg} / \mathrm{g})$ and standard errors (SE) of sodium nitrite (SN) detected in the tissues and undigested bait from invasive wild pigs after consuming $400 \mathrm{mg} / \mathrm{kg}$ (body weight) of SN in the toxic bait containing four micro-encapsulation coatings in pens at the Kerr Wildlife Management Area, Hunt, TX, USA during 2014

\begin{tabular}{|c|c|c|c|c|c|c|c|c|c|c|c|c|c|c|}
\hline \multirow{3}{*}{$\begin{array}{l}\text { Micro-encapsulation } \\
\text { treatment }\end{array}$} & \multicolumn{14}{|c|}{ Residual sodium nitrite $(\mathrm{mg} / \mathrm{g})$} \\
\hline & \multicolumn{2}{|c|}{ Muscle } & \multicolumn{2}{|c|}{ Liver } & \multicolumn{2}{|c|}{ Eye } & \multicolumn{2}{|c|}{ Stomach } & \multicolumn{2}{|c|}{ Small intestine } & \multicolumn{2}{|c|}{ Stomach contents } & \multicolumn{2}{|c|}{ Vomitus } \\
\hline & Mean & SE & Mean & SE & Mean & SE & Mean & SE & Mean & SE & Mean & SE & Mean & SE \\
\hline Protein (single) & $0.003^{\mathrm{A}}$ & 0.0009 & $0.006^{\mathrm{A}}$ & 0.001 & $0.004^{\mathrm{A}}$ & 0.0009 & $0.78^{\mathrm{B}}$ & 0.11 & $0.83^{A, B}$ & 0.29 & $11.51^{\mathrm{B}}$ & 2.58 & $11.98^{\mathrm{A}}$ & 2.23 \\
\hline Protein (double) & $0.003^{\mathrm{A}}$ & 0.0006 & $0.006^{\mathrm{A}}$ & 0.002 & $0.002^{\mathrm{A}}$ & 0.0002 & $0.82^{\mathrm{B}}$ & 0.15 & $1.63^{\mathrm{B}}$ & 0.57 & $12.74^{\mathrm{B}}$ & 2.67 & $14.76^{\mathrm{A}}$ & 3.47 \\
\hline Soft wax & $0.001^{\mathrm{A}}$ & 0.0001 & $0.003^{A}$ & 0.001 & $0.006^{\mathrm{B}}$ & 0.001 & $0.80^{\mathrm{B}}$ & 0.18 & $0.33^{A, B}$ & 0.85 & $9.31^{\mathrm{B}}$ & 2.37 & $9.56^{\mathrm{A}}$ & 0.49 \\
\hline Resin & $0.002^{\mathrm{A}}$ & 0.0003 & $0.005^{\mathrm{A}}$ & 0.003 & $0.005^{\mathrm{B}}$ & 0.001 & $0.56^{\mathrm{B}}$ & 0.26 & $0.27^{A, B}$ & 0.80 & $13.93^{\mathrm{B}}$ & 4.64 & $10.38^{\mathrm{A}}$ & 1.93 \\
\hline Control & $0.002^{\mathrm{A}}$ & 0.0001 & $0.005^{\mathrm{A}}$ & 0.003 & $0.002^{A}$ & 0.0001 & $0.007^{A}$ & 0.003 & $0.03^{A}$ & 0.004 & $0.008^{A}$ & 0.0001 & NA & NA \\
\hline
\end{tabular}

Superscript letters signify statistical differences among the micro-encapsulation treatments at the level of $\alpha=0.05$ within the sample groups.

For both analyses, we examined the parameter estimates $(\beta)$ and $95 \%$ confidence intervals (Cls) of the interaction for a lack of overlap of 0 to indicate statistical and biological influences on the persistence of SN.

\subsection{Risk assessment}

To our knowledge, we identified and evaluated the widest ranges of data available on sensitivity to $\mathrm{SN}$ for mammalian and avian species to provide insight on risk of secondary poisoning for scavengers that may consume tissues of wild pig carcasses. For mammalian species, we identified the lowest reported $L_{50}$ value of $58 \mathrm{mg} / \mathrm{kg}$ (body weight) for raccoons (Procyon lotor) ${ }^{31}$ and the highest reported value of $525 \mathrm{mg} / \mathrm{kg}$ (body weight) for black rats (Rattus rattus). ${ }^{32}$ For avian species, we identified the lowest reported $L_{50}$ value of $68.5 \mathrm{mg} / \mathrm{kg}$ (body weight) for domestic chickens (Gallus gallus domesticus) and domestic mallard ducks (Anas platyrhynchos domestica), ${ }^{33}$ and the highest reported value of $619 \mathrm{mg} / \mathrm{kg}$ (body weight) for northern bobwhite (Colinus virginianus). ${ }^{34}$ We used these ranges of $\mathrm{LD}_{50}$ values to represent a general range of risk for mammalian and avian species that may scavenge carcasses of wild pigs. We calculated ranges of \% live body mass that each class of scavenger would need to consume during a single-feeding event to be put at risk from SN, using the following formula:

$$
\frac{\left[\frac{\mathrm{LD}_{50} \text { value } \times \text { scavenger live body mass }}{\text { residual } \mathrm{SN} \text { in IWP tissues }}\right]}{\text { Scavenger live body mass }}
$$

Finally, we used the values from above to calculate the \% daily diet that a scavenger would need to consume during a single-feeding event to be put at risk from SN. We calculated the mean and $95 \% \mathrm{Cl}$ for daily diet requirements $(\mathrm{g})$ using allometric equations for field metabolic rates of dry matter food..$^{35}$ We multiplied the daily dry matter amounts by $3.33 \mathrm{~g}$ of fresh matter per $1 \mathrm{~g}$ of dry matter to convert dry matter to daily fresh matter intake. ${ }^{35}$ Specifically, we calculated daily fresh matter intake for three common non-target species that may consume tissues or undigested bait from carcasses of wild pigs, including (1) an average sized coyote (Canis latrans; $15 \mathrm{~kg}$ ) to represent a mammalian scavenger, (2) an average sized raccoon ( $7 \mathrm{~kg}$ ) to represent a meso-ominvore, and (3) an average size turkey vulture (Cathartes aura; $2 \mathrm{~kg}$ ) to represent an avian scavenger.

\section{RESULTS}

\subsection{Micro-encapsulation treatments}

All of the MESN treatments were $100 \%$ effective at killing wild pigs, except the resin treatment, where one animal survived (Table 1). We detected no differences in the proportion of wild pigs that vomited among the treatment groups $(P=0.766)$, with a total of 17 of $24(70.8 \%)$ wild pigs vomiting at least once. On average, the first vomiting occurred $2.3 \mathrm{~h}(\mathrm{SE}=0.15)$ post-consumption, quickly followed by death at $2.7 \mathrm{~h}(\mathrm{SE}=0.14)$, excluding the resin treatment group. None of the control animals showed any vomiting or symptoms of intoxication throughout the study.

\subsection{Residual SN in tissues and undigested bait}

We excluded the lone surviving wild pig from the resin treatment group from analyses of residual SN in tissues and stomach 
Immediate response (hours)

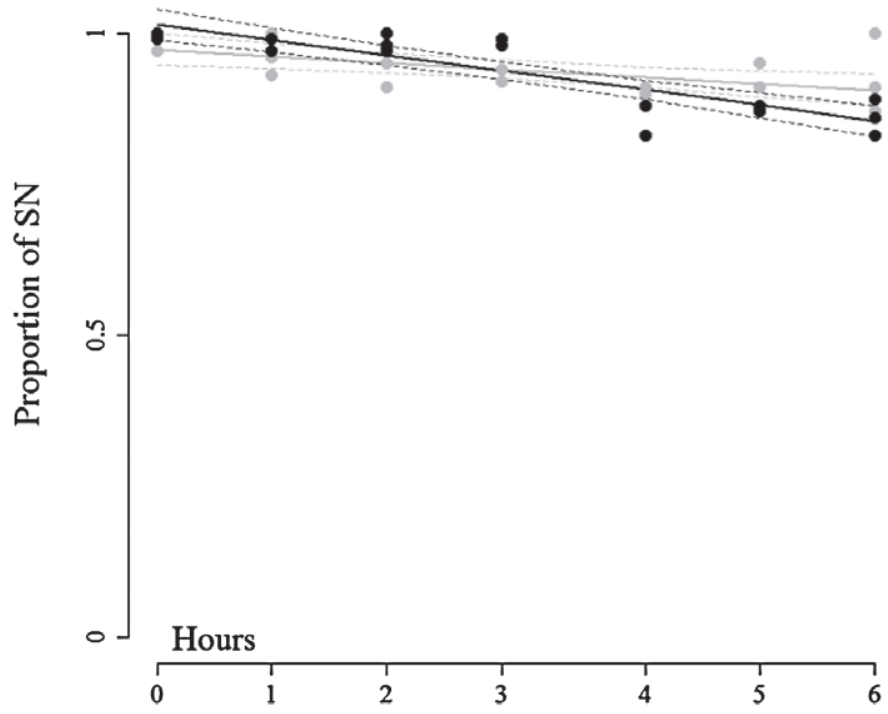

Long-term response (days)

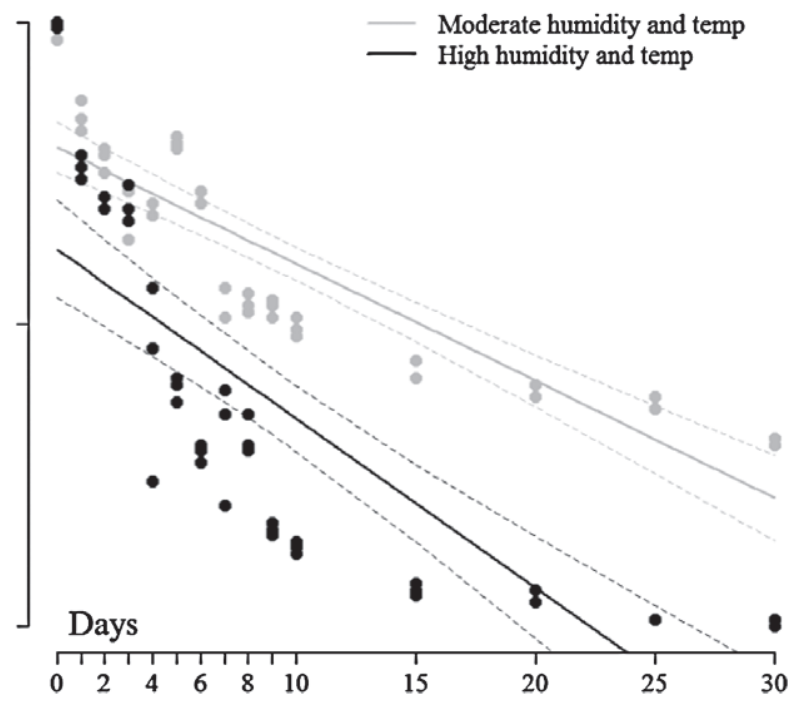

Figure 1. Fitted linear regression lines (solid lines) with $95 \%$ confidence intervals (dotted lines) and associated data (points) showing reduction of sodium nitrite (SN) in the vomitus of the toxic bait through time under two environmental conditions collected from captive invasive wild pigs at the Kerr Wildlife Management Area, Hunt, Texas, USA. The toxic bait was comprised of $10 \%$ SN (100 mg/g SN) of which invasive wild pigs were dosed at $400 \mathrm{mg} / \mathrm{kg}$ (body weight) of $\mathrm{SN}$. The level of residual $\mathrm{SN}$ at time $t=0$ when regurgitation occurred averaged $10.9 \mathrm{mg} / \mathrm{g}(\mathrm{SE}=0.07)$, equating to $1.09 \% \mathrm{SN}$ in the vomitus.

contents. For all other wild pigs, the average levels of SN were not different between treatment and control animals in muscle $\left(F_{4,22}=2.18, P=0.105\right.$; Table 2$)$ and liver tissues $\left(F_{4,22}=0.53\right.$, $P=0.716)$. For the eye tissue, two of the treatment groups had higher levels of $\mathrm{SN}$ than in control animals $\left(\mathrm{F}_{4,22}=4.15, P=0.012\right)$, although all levels were low. For the stomach tissues, all treatments had higher levels of SN compared to control animals $\left(F_{4,22}=3.39, P=0.026\right)$. For the small intestine tissues, only the double-coated protein treatment group had statistically higher levels of SN compared to control animals $\left(F_{4,22}=3.84, P=0.016\right)$, albeit all treatment groups had noticeably higher levels of $S N$ than control animals. For the stomach contents, all of the treatments had higher levels of SN compared to control animals $\left(\mathrm{F}_{4,22}=2.92\right.$, $P=0.044)$. Lastly, there were no differences in the residual $\mathrm{SN}$ in vomitus among the treatment groups $\left(F_{3,13}=0.75, P=0.541\right)$.

For the single pig that survived in the resin treatment group ( $26 \mathrm{~kg}$, male), the SN had been metabolized or broken down, and was undetectable in tissues in $\leq 24 \mathrm{~h}$. The animal appeared fully recovered at this time showing no symptoms of SN intoxication (e.g. labored breathing, incoordination, etc.). The muscle, liver, and eye all contained $<0.003 \mathrm{mg} / \mathrm{g}$ of SN each. The stomach contained $0.005 \mathrm{mg} / \mathrm{g}$, the small intestine contained $0.014 \mathrm{mg} / \mathrm{g}$, and the stomach contents contained $0.008 \mathrm{mg} / \mathrm{g}$ of SN.

\subsection{Environmental persistence of $\mathrm{SN}$ in vomitus}

The average concentration of $\mathrm{SN}$ in freshly regurgitated vomitus $(t=0)$ was $10.9 \mathrm{mg} / \mathrm{g}(\mathrm{SE}=0.07)$, equating to vomitus comprised of $1.09 \% \mathrm{SN}$. Analysis of the first $6 \mathrm{~h}$ indicated that the interaction of time $\times$ climate had a significant influence on the decrease of SN ( $\beta=8.6495 \% \mathrm{Cl}=7.62-22.60)$. In particular, vomitus in the high humidity and temperature climate had a greater decrease in SN than in the moderate climate through time, albeit both climates had slight decreases through time (Fig. 1). The same trend was even more evident in the longer-term analysis $(\beta=0.13$, $95 \% \mathrm{Cl}=0.09-0.17$; Fig. 1 ). In the high humidity and temperature climate, the SN had decreased nearly 100\% in 25 days (Fig. 1). The moderate climate also had substantial decreases in SN, but less than the hot and humid climate.

\subsection{Risk assessment}

Digestive tracts (i.e. stomach, stomach contents, and small intestines) were the only components of wild pig carcasses we measured with elevated residues of SN (average $=4.35 \mathrm{mg} / \mathrm{g}$, excluding wild pigs from the resin treatment group). Based on this average, we estimated that mammalian scavengers would have to consume $1.33-12.08 \%$ of their body mass of wild pig digestive tract during a single-feeding event to be put at risk of secondary poisoning. Similarly, we estimated that avian scavengers would need to consume $1.58-14.25 \%$ of their body mass during a single-feeding event.

Coyotes that consume an average of $1567 \mathrm{~g} \quad(95 \%$ $\mathrm{Cl}=536-4,579)$ of fresh matter daily would need to consume $13-116 \%$ of their daily dietary requirement (i.e. $200-1810 \mathrm{~g}$ ) of digestive tract tissues or undigested bait in a single-feeding event to potentially be at risk of secondary poisoning from SN. Raccoons that consume $580 \mathrm{~g}(95 \% \mathrm{Cl}=220-1530)$ of fresh matter daily would have to consume $16-147 \%$ of their daily dietary requirement (i.e. $100-800 \mathrm{~g}$ ) in a single-feeding event to be at risk. Finally, turkey vultures that consume $228 \mathrm{~g}(95 \% \mathrm{Cl}=89-584)$ of fresh matter daily would need to consume $14-125 \%$ of their daily dietary requirement (i.e. $30-280 \mathrm{~g}$ ) in a single-feeding event to be at risk.

\section{DISCUSSION}

Overall, this study provided important information for understanding the potential secondary poisoning risks associated with wild pigs that consume a MESN toxic bait. None of the tested micro-encapsulation coatings appeared to offer less risk than the single-coated protein that is currently used to manufacture the 
toxic bait, and currently used in New Zealand. The protein (single and double) and soft wax coatings had similar characteristics in time-to-first-vomit, time-to-death, residual SN, and efficacy. These three coatings appeared to release the SN similarly, and allow rapid absorption into the bloodstream resulting in a severe methemoglobinemia and quick death (mean $=2.7 \mathrm{~h}$ from dosing). The resin coating appeared to have a slower release of SN with higher variability, and subsequently had a delayed time-to-death $($ mean $=12.4 \mathrm{~h}$ ). One wild pig survived in this treatment group, likely because the $\mathrm{SN}$ was metabolized quickly enough to counteract the variable release.

We found that $\geq 50 \%$ of fasted wild pigs vomited at least once after administering a rapid and lethal dose of the toxic bait in this study, regardless of which formulation of micro-encapsulation coating was used. The exact mechanism triggering the regurgitation could not be determined using this study design, but is likely related to the release of $\mathrm{SN}$ or the degradation of nitrite into nitric oxide gas following the breakdown of the micro-encapsulation coating and subsequent dissociation of SN. ${ }^{36}$ Toxic baiting in more natural settings may reduce vomiting because wild pigs are unlikely to be fasted. Observations of vomitus in the field suggest that vomiting was infrequent in field trials in Australia. ${ }^{21}$

It is unknown whether non-target animals will consume vomitus of a toxic bait that contains SN. We suspect vomitus could be aversive to scavengers because the $\mathrm{SN}$ is exposed to the digestive tract, leading to a breakdown of the micro-encapsulation and therefore is no longer protected from degradation and detection by non-target animals. The micro-encapsulation coating dissolves (except resin coating) in the stomach of wild pigs when exposed to hydrochloric acid, digestive enzymes, and water; therefore, the vomitus likely acquires a strong salt flavor and exhibits aversive taste and odor from the SN breakdown. Ultimately, the residual $\mathrm{SN}$ oxidizes to harmless nitrates as part of the nitrogen cycle. Also, reduction of nitrite may occur and produce nitric oxide gas with a noticeable odor ${ }^{37}$ that is likely aversive.

Our results show that the MESN toxic bait lost $~ 90 \%$ of SN in the stomach of wild pigs prior to any vomiting (i.e. within $2.3 \mathrm{~h}$ ). After 1 week of exposure to the environment, $\leq 0.5 \%$ of the original $\mathrm{SN}$ was detected in the vomitus of the MESN toxic bait, although this is conservative because no leeching of the $\mathrm{SN}$ occurred during our laboratory test (e.g. rain would rapidly remove $\mathrm{SN}$ residues). We were unable to accurately weigh the amount of vomitus from each wild pig because the vomitus was usually a liquid consistency and not all of it could be retrieved. Visual observations suggest that the amount of undigested bait in the vomitus varied widely but was often small relative to the amount of bait consumed. The consistency and often scarce amounts of vomitus expelled suggest that the risk of scavengers finding and consuming enough vomitus to ingest a rapid bolus dose of SN that would be required for a lethal sequel is low.

Our findings confirm that the majority of a wild pig carcass will not be hazardous to non-target species, similar to previous findings with MESN toxic baits. ${ }^{21,26}$ The US Food and Drug Administration regulates that no more than $0.2 \mathrm{mg} / \mathrm{g}$ of $\mathrm{SN}$ be allowed as a food additive for human consumption in finished meat products. ${ }^{38}$ Extrapolating this concentration to wildlife, we conclude that consumption of the muscle, liver and eye tissues of a wild pig carcass immediately after death is nonhazardous to non-target species, including humans. The digestive tract (i.e. stomach, stomach contents and small intestines) averaged $\sim 22$ times this dose at the time of death, and therefore may pose some risk.
From our risk assessment we found that coyotes, raccoons and turkey vultures would need to consume approximately $\geq 15 \%$ of their daily dietary requirements of digestive tract tissues or undigested bait in a rapid, single-feeding event to be at moderate risk, based on $\mathrm{LD}_{50}$ values reported for mammalian and avian species. This finding of is conservative for a few reasons. Primarily, the $\sim 15 \%$ value is based on the most conservative $\mathrm{LD}_{50}$ estimates reported for mammalian and avian species, and then extrapolated. Some species may be less susceptible to SN based on higher levels of methemoglobin reductase enzymes for converting methemoglobin back to hemoglobin. ${ }^{39}$ Using less conservative $L_{50}$ values reveals that scavengers would need to consume more than their daily dietary requirements $(\geq 116 \%)$ in a single-feeding event to be at risk. Second, the reported values of $\mathrm{LD}_{50}$ were obtained from studies that used oral gavage to administer $\mathrm{SN}$, and therefore represent more acute estimates of risk compared to free-feeding animals. For example, wild pigs and domestic chickens were approximately four times less sensitive to $\mathrm{SN}$ in free-feeding trails than in oral gavage trials. ${ }^{17,33}$ Third, the residues of $\mathrm{SN}$ continue breaking down into less toxic forms (i.e. nitrate or nitric oxide) as carcasses age, therefore the digestive tracts likely become less toxic through time. ${ }^{21}$ Turkey vultures and black vultures (Coragyps atratus) reportedly take $\sim 24 \mathrm{~h}$ to begin scavenging on pig carcasses in Texas. ${ }^{40}$ Finally, this risk assessment assumes that scavengers would consume only the digestive tract during a single-feeding event, but likely scavengers would also consume other tissues (e.g. muscle) and dilute or minimize the amount of digestive tract consumed.

Scavengers would have to consume the digestive tract rapidly (e.g. within a single-feeding event) to experience toxic effects because $\mathrm{SN}$ toxicity is dependent on circulating methemoglobin concentration. If scavengers consumed the digestive tract slowly (e.g. over multiple hours) the SN will be metabolized and cleared from the circulation, and unlikely to be lethal. Most carcasses are not $100 \%$ consumed by scavengers ${ }^{41}$ lessening the risks that only digestive tracts are consumed. For example, black bears (Ursus americanus) typically avoid consuming digestive tracts, ${ }^{42}$ and therefore likely experience low risk. Coyotes prefer to consume muscle tissue ${ }^{42}$ but may consume digestive tracts during times of scarce resources, and therefore may experience some risk. Turkey vultures and black vultures will consume entire carcasses ${ }^{40}$ but over a period of multiple days, ${ }^{43}$ which therefore reduces their risk. Avian scavengers also did not prefer stomachs and stomach content from carcasses of wild pigs in Texas leaving those as the last items to be consumed. ${ }^{44} \mathrm{~A}$ more thorough, probabilistic risk assessment accounting for all these factors is needed to quantitatively inform the risks of secondary poisoning for these scavengers.

Based on our findings, the risks of secondary poisoning for humans that may harvest a wild pig exposed to MESN toxic bait are negligible. Primarily, there is little opportunity for humans to harvest wild pigs exposed to MESN toxic bait because the time to death is $<3 \mathrm{~h}$. However, if a poisoned wild pig was harvested, consumption of muscle tissue would not be hazardous because $\mathrm{SN}$ residues are well below the recommended amount for human consumption. ${ }^{38}$ In addition, a poisoned wild pig would be easily detected and consumption avoided because severe methemoglobinemia turns the blood a noticeable dark brown color. ${ }^{45}$ The only risk to humans would occur if a human consumed the digestive tract of a poisoned wild pig. A $68 \mathrm{~kg}$ human would need to consume $0.91-8.22 \mathrm{~kg}$ of digestive tract during a single feeding to be put at risk of secondary poisoning, which is unlikely. 
An important observation from this study involves the single wild pig that survived exposure to an expected lethal dose of the MESN toxic bait. By the time this animal was euthanized (i.e. $24 \mathrm{~h}$ post-ingestion), the animal appeared fully recovered and had no evidence of residual SN. This suggests that sublethal doses of SN are rapidly metabolized and do not bio-accumulate in the tissues. This is an important consideration for wild pigs, as well as the predators and scavengers of wild pigs that may be exposed to low levels of SN. No debilitating effects appeared to occur from sublethal dosing in this study, or in another study with other species. $^{33}$

\section{CONCLUSION}

We found no evidence that use of alternative micro-encapsulation coatings would be beneficial compared to the currently used formulation of the MESN toxic bait. Vomiting appears to be a frequent outcome of MESN toxic bait delivered to wild pigs under these study conditions (i.e. ingestion of a rapid and lethal, bolus dose). However, the level of secondary risk from vomitus to non-target species appears low because $\sim 90 \%$ of the SN has already left the bait, and continues to breakdown in vomitus once exposed to the environment. Carcasses of wild pigs contain low levels of residual SN and are not likely to be risky for scavengers to consume, except for the digestive tract. If mammalian or avian scavengers consume enough of the digestive tract secondary poisoning could occur. However, the risk is lessened because consumption would need to occur rapidly (i.e. during a single-feeding event) from a fresh wild pig carcass in which the SN has not had time to breakdown. Sublethal doses of SN are rapidly metabolized without debilitating effects.

\section{ACKNOWLEDGEMENTS}

We thank C. Blass, J. Halseth, J. Kinsey, M. Lavelle, G. Lawrence, and J. C. Martin for assisting with data collection. J. Kinsey, G. Lawrence, and J. C. Martin developed the technique for dosing wild pigs. We thank B. Hall and T. Larosa from Animal Control Technologies $\mathrm{P} / \mathrm{L}$, and P. Aylet and D. McMorran from Connovation Ltd for producing and shipping test materials. We thank the NWRC Chemistry Unit and Southwest Research Institute for conducting chemical analyses. Test subjects were provided primarily by the Texas USDA/APHIS/Wildlife Services. We thank anonymous reviewers for their comments on this manuscript. Mention of commercial products or companies does not represent an endorsement by the US government.

\section{REFERENCES}

1 Keiter DA, Mayer JJ and Beasley JC, What is in a "common" name? A call for consistent terminology for nonnative Sus scrofa. Wildlife Soc Bull 40:384-387 (2016).

2 Snow NP, Jarzyna MA and VerCauteren KC, Interpreting and predicting the spread of invasive wild pigs. J Appl Ecol http://doi.org/10.1111/1365-2664.12866 (2017).

3 Barrios-Garcia MN and Ballari SA, Impact of wild boar (Sus scrofa) in its introduced and native range: a review. Biological Invasions 14:2283-2300 (2012).

4 Pimentel D, Lach L, Zuniga R and Morrison D, Environmental and economic costs of nonindigenous species in the United States. BioScience 50:53-65 (2000).

5 Pimentel D. Environmental and economic costs of vertebrate species invasions into the United States, in Managing Vertebrate Invasive Species: Proceedings of An International Symposium, ed. by Witmer
GW, Pitt WC and Fagerstone KA. U.S. Department of Agriculture, Animal and Plant Health Inspection Service, Wildlife Services, National Wildlife Research Center, Fort Collins, CO, USA, pp. 2-8 (2007).

6 Hone J, Spatial and temporal aspects of vertebrate pest damage with emphasis on feral pigs. J Appl Ecol 32:311-319 (1995).

7 Anderson A, Slootmaker C, Harper E, Holderieath J and Shwiff SA, Economic estimates of feral swine damage and control in 11 US states. Crop Prot 89:89-94 (2016).

8 Dickson JG, Mayer JJ and Dickson JD. Wild hogs, in Wildlife of Southern Forests: Habitat and Management, ed. by Dickson JG. Hancock House Publishers, Blaine, WA, pp. 191-208 (2001).

9 Adams CE, Lindsey KJ and Ash SJ. Urban Wildlife Management. CRC Press, Boca Raton, FL (2006).

10 Hahn E, Page G, Hahn P, Gillis K, Romero C, Annelli J et al., Mechanisms of transmission of Aujeszky's disease virus originating from feral swine in the USA. Vet Microbiol 55:123-130 (1997).

11 Doran RJ and Laffan SW, Simulating the spatial dynamics of foot and mouth disease outbreaks in feral pigs and livestock in Queensland, Australia, using a susceptible-infected-recovered cellular automata model. Prev Vet Med 70:133-152 (2005).

12 Hone J, Feral pigs in Namadgi National Park, Australia: dynamics, impacts and management. Biological Conservation 105:231-242 (2002).

13 Taylor RB and Hellgren EC, Diet of feral hogs in the western South Texas Plains. The Southwestern Naturalist 42:33-39 (1997).

14 Jolley DB, Ditchkoff SS, Sparklin BD, Hanson LB, Mitchell MS and Grand $J B$, Estimate of herpetofauna depredation by a population of wild pigs. J Mammalogy 91:519-524 (2010).

15 Fordham D, Georges A, Corey B and Brook BW, Feral pig predation threatens the indigenous harvest and local persistence of snake-necked turtles in northern Australia. Biological Conservation 133:379-388 (2006).

16 van Riper C and Scott J, Limiting factors affecting Hawaiian native birds. Studies in Avian Biology 22:221-233 (2001).

17 Cowled BD, Elsworth P and Lapidge SJ, Additional toxins for feral pig (Sus scrofa) control: identifying and testing Achilles' heels. Wildlife Res 35:651-662 (2008).

18 Shapiro L, Eason C, Bunt C, Hix S, Aylett P and MacMorran D, Efficacy of encapsulated sodium nitrite as a new tool for feral pig management. J Pest Sci 89:489-495 (2016).

19 Sharp T and Saunders G, Model Code of Practice for the Humane Control of Feral Pigs. [Online]. Department of Sustainability, Environment, Water, Population and Communities, Invasive Animals Cooperative Research Centre (2012). Available: http://www.pestsmart.org.au/wpcontent/uploads/2012/09/pigCOP2012.pdf [14 March 2017].

20 Cowled B and O'Connor C. A Project That Investigates Current Options for Managing Feral Pigs in Australia and Assesses the Need for the Development of More Effective and Humane Techniques and Strategies - Stage 3 Report. [Online]. Pest Animal Control Cooperative Research Centre, Canberra, Australia (2004). Available: http://www.pestsmart.org.au/ a-project-that-investigates-current-options-for-managing-feralpigs-in-australia-and-assesses-the-need-for-the-development-ofmore-effective-and-humane-techniques-and-strategies-\%E2\%80 \%93-stage-3-repo/ [14 March 2017].

21 Lapidge S, Wishart J, Staples L, Fagerstone K, Campbell T and Eisemann J. Development of a feral swine toxic bait (Hog-Gone $\left.{ }^{\circledR}\right)$ and bait hopper (Hog-Hopper ${ }^{\mathrm{TM}}$ ) in Australia and the USA, in Proceedings of the 14th Wildlife Damage Management Conference, ed. by Frey SN. University of Lincoln, Nebraska, pp. 19-24 (2012).

22 Institute of Medical and Veterinary Science, Assessing the Humaneness and Efficacy of A New Feral Pig Bait in Domestic Pigs. [Online]. Australian Government Department of the Environment, Water, Heritage and the Arts. Canberra, Australia (2010). Available: http:// www.environment.gov.au/system/files/resources/091b0583-f35c40b3-a530-f2e0c307a20c/files/pigs-imvs-report.pdf [9 May 2016].

23 Eason CT, Miller A, MacMorran DB and Murphy EC, Toxicology and ecotoxicology of para-aminopropiophenone (PAPP) - a new predator control tool for stoats and feral cats in New Zealand. NZ J Ecol 38:177-188 (2014).

24 Snow NP, Foster JA, Kinsey JC, Humphrys ST, Staples LD, Hewitt DG et al., Development of toxic bait to control invasive wild pigs and reduce damage. Wildlife Soc Bull 41:256-263 (2017).

25 Snow NP, Halseth JM, Lavelle MJ, Hanson TE, Blass CR, Foster JA et al., Bait preference of free-ranging feral swine for delivery of a novel toxicant. PLoS ONE 11:e0146712 (2016). 
26 Shapiro L, The potential of sodium nitrite as a new tool for vertebrate pest control from formulation, efficacy and safety perspectives. PhD dissertation, Lincoln University, NZ (2016).

27 Shapiro L, MacMorran D, Eason C and Bunt C, Zein Coated Sodium Nitrite for Brushtail Possum Control. Controlled Release Society Annual Meeting, Honolulu, Hawaii (2013).

28 Shapiro L, Eason C, Bunt C, Hix S, Aylett P and MacMorran D, Encapsulated sodium nitrite as a new toxicant for possum control in New Zealand. NZ J Ecol 40:381 - 385 (2016).

29 Leary S, Underwood W, Anthony R, Cartner S, Corey D, Grandin T et al., AVMA Guidelines for the Euthanasia of Animals, 2013 edition. American Veterinary Medical Association, Schaumburg, IL (2013).

30 Cribari-Neto F and Zeileis A, Beta regression in R. J Stat Software 34:1-24 (2010)

31 Foster JA, Effects of Sodium Nitrite on Feral Swine and Non-targets, unpublished final report, TDA Project No. FH-10-05. Texas Department of Agriculture Performance Report, TX (2011).

32 Witmer GW, A Preliminary Evaluation of Sodium Nitrite As A Rodenticide, unpublished final report, QA-1752. USDA/APHIS/WS National Wildlife Research Center, CO (2013).

33 Shapiro L, Aylett $\mathrm{P}$, Arthur D and Eason C, Primary poisoning risk for encapsulated sodium nitrite, a new tool for pest control. NZ J Zool (in press) (2017).

34 Stafford J, Northern Bobwhite (Colinus virginianus) Acute Oral Toxicity Test (LD50) with Sodium Nitrite, unpublished final report, No. 13998.4100. Smithers Viscient, Carolina Research Center, Snow Camp, NC (2011)

35 Nagy KA, Girard IA and Brown TK, Energetics of free-ranging mammals, reptiles, and birds. Annu Rev Nutr 19:247-277 (1999).

36 Braida W and Ong SK, Decomposition of nitrite under various $\mathrm{pH}$ and aeration conditions. Water Air Soil Pollut 118:13-26 (2000).
37 National Center for Biotechnology Information, Nitrous oxide, in PubChem Compound Database. PubChem (2017). Available: https://pubchem.ncbi.nlm.nih.gov/compound/948 [9 March 2017].

38 US Food and Drug Administration, Code of Federal Regulations Title 21. US Department of Health and Human Services (2016). Available: https://www.accessdata.fda.gov/scripts/cdrh/cfdocs/cfcfr/ CFRSearch.cfm?CFRPart=172\&showFR=1 [6 March 2017].

39 Lapidge SJ and Eason CT, Pharmacokinetics and Methaemoglobin Reductase Activity as Determinants of Species Susceptibility and Non-target Risks from Sodium Nitrite Manufactured Feral Pig Baits. Australian Government Department of the Environment, Water, Heritage and the Arts, Canberra (2010).

40 Reeves NM, Taphonomic effects of vulture scavenging. J Forensic Sci 54:523-528 (2009).

41 DeVault TL, Rhodes Jr OE and Shivik JA, Scavenging by vertebrates: behavioral, ecological, and evolutionary perspectives on an important energy transfer pathway in terrestrial ecosystems. Oikos 102:225-234 (2003).

42 Wade D and Browns J, Procedures for Evaluating Predation on Livestock and Wildlife, Bulletin No. B-1429. Texas Agricultural Extension Service, Texas A\&M University, San Angelo (1982).

43 Buckley NJ, Experimental tests of the information-center hypothesis with black vultures (Coragypsatratus) and turkey vultures (Cathartesaura). Behavioral Ecology and Sociobiology 41:267-279 (1997).

44 Martin JC, Investigation of sodium nitrite as a control tool for feral pigs. MS thesis, Sul Ross State University (2015).

45 Patton TG, Blamer SL and Horak KE, Detecting methemoglobinemia in animals with a drop of blood. PLoS One 11:e0167942 (2016). 